\title{
Temporal-Spatial Characteristics of Ground and Pile Responses to Twin Shield Tunneling in Clays
}

\author{
Minghong Sheng, ${ }^{1,2}$ Jinjin Gao $\mathbb{D}^{3},{ }^{3}$ Panpan Guo $\mathbb{D}^{4},{ }^{4}$ Rihong Cao, ${ }^{5}$ and Yixian Wang $\mathbb{D}^{6}$ \\ ${ }^{1}$ School of Management, Hefei University of Technology, Hefei 230009, China \\ ${ }^{2}$ Anhui Road \& Bridge Group Co. Ltd., Hefei 210029, China \\ ${ }^{3}$ Center for Strategic Studies, Chinese Academy of Engineering, Beijing 100088, China \\ ${ }^{4}$ Research Center of Coastal and Urban Geotechnical Engineering, Zhejiang University, Hangzhou 310058, China \\ ${ }^{5}$ The University of Western Australia, Perth WA 6009, Australia \\ ${ }^{6}$ School of Civil Engineering, Hefei University of Technology, Hefei 230009, China
}

Correspondence should be addressed to Jinjin Gao; gjj@cae.cn and Yixian Wang; wangyixian2012@hfut.edu.cn

Received 8 April 2021; Revised 3 June 2021; Accepted 21 June 2021; Published 7 July 2021

Academic Editor: Afshin Davarpanah

Copyright () 2021 Minghong Sheng et al. This is an open access article distributed under the Creative Commons Attribution License, which permits unrestricted use, distribution, and reproduction in any medium, provided the original work is properly cited.

\begin{abstract}
This paper investigates the temporal-spatial characteristics of ground displacements as well as vertical and horizontal displacements and axial forces in existing piles induced by twin shield tunneling in clays. To that end, a case study and three-dimensional (3D) finite element (FE) analysis were performed. Based on the in situ monitoring data from the presented twin tunneling case history with existing piles beneath, the adopted 3D FE method was validated to be competent to yield reasonable simulation results. The validated 3D FE method was then used to analyze the effects of the distance between the tunnel and the pile, the distance between tunnel faces, and the pile length on the horizontal and vertical displacements and axial stresses in piles. It was found that the horizontal displacement distribution forms along the pile shaft for the front piles are similar to that for the back piles, whereas the magnitudes of the horizontal displacements of the front piles are slightly larger than that of the back piles. The interactions between piles in the pile group provide protection of the middle piles in the pile group against twin tunneling effects. With a reduction in the distance between the tunnel and the pile, the pile displacements and stresses increase nonlinearly. With an increase in the distance between tunnel faces, the maximum positive pile displacements and the maximum and minimum axial pile stresses increase, while the maximum negative pile displacements and the difference between the maximum and minimum axial pile stresses decrease.
\end{abstract}

\section{Introduction}

In congested urban cities, one of the effective means of relieving traffic pressure is to construct metros. The metro tunnels, in many cases, are adjacent to pile-supported structures $[1,2]$. Studies have indicated that tunneling adjacent to pile-supported structures can induce ground movements [3], excessive lateral pile displacements [4], and reduction in structure bearing capacity and stability [5]. This will pose serious risks to people's lives and properties. Consequently, it is significant to investigate tunneling-induced ground movements and pile group responses [6-11].
Prediction of ground movements induced by tunneling can be made employing numerical analyses $[12,13]$, analytical expressions [14-16], artificial neural networks [17], and empirical methods [18]. The empirical methods have been proposed on the basis of the Gaussian error function [1922] and are widely used in engineering practices because of convenience and simplicity [23]. However, limitations of the empirical methods exist, which include taking no account of the tunnel geometry, ground condition, and construction technique and providing insufficient information about subsurface settlements and horizontal displacements $[24,25]$.

Tunneling-induced ground movements affect the responses of the adjacent pile group because of the tunnel- 
soil-structure interaction effect [26, 27]. This effect is dependent on factors such as the location of the pile relative to the tunnel, pile working load, cover-to-diameter ratio, and pile and tunnel dimensions [28]. To better understand this vital issue, researchers have carried out numerous studies based on different methods such as field monitoring [29], theoretical analysis [30], numerical simulation [31], and experimental investigation [32]. Actually, each of these methods has its own merits. The merits of numerical simulation, for example, are being able to account for the tunnel-soil-pile interaction effect, soil heterogeneity, and complex boundary conditions [33].

Pile group responses to tunneling can vary slightly, depending on the characteristics of the stratum in which tunneling occurs [34-36]. Studies on pile group responses to tunneling in a clay stratum are available in the literature. Ieronymaki et al. [37] conducted a comparative study into the effects of methods of tunneling in stiff clay on ground movements. It was found that the closed-face method controlled best the volume loss, while the open-face shield excavation method produced the largest tunnel cavity ovalization. Cattoni et al. [38] investigated the coupled hydromechanical processes related to shield tunneling in soft clays. A new method for predicting the displacement and internal force of constructed tunnels induced by adjacent excavation with dewatering was proposed by Guo et al. [35]. Using the force relaxation technique and finite difference program, Shiau et al. [39] analyzed the ground settlements induced by circular tunneling in soft clay. Son [40] made an analysis of structure responses to ground movements induced by tunneling in clay soils. Wang and Li [36] investigated the deformation and failure of surrounding rock after tunnel excavation under different joint network and groundwater conditions. Laver et al. [41] proposed a new method of estimating long-term ground movements induced by tunneling in London clay. Sun et al. [42] performed three-dimensional coupled consolidation finite element analyses to study the influence of consolidation on the tunnel response to excavation. However, the focus of most of these studies is on single-line tunnels. The effects of twin tunneling in a thick clay stratum on ground movements and pile group responses have not been fully captured.

Twin tunneling is becoming common with the development of urban underground traffic systems [43-45]. However, the number of studies available into the effects of twin tunneling on ground movements and pile group responses is limited. Moreover, most of the studies available are mainly focused on the effects of twin tunneling in dry sand [46-48]. Thus, twin tunneling-induced ground movements and pile group responses still remain poorly understood, especially for twin tunneling in a thick clay stratum.

The present study is targeted at investigating the ground surface settlements and pile group responses induced by twin tunneling in clays. 3D finite element analysis was performed to capture the development of ground surface settlements and pile group responses with advancing tunneling steps and to ascertain the effects of the distance between the tunnel and the pile, the distance between tunnel faces, and the pile length on the pile group responses on completion of tunnel- ing. The performance of the 3D finite element analysis has been verified by the in situ monitoring data. The results obtained in this study have the potential to guide the protection of the pile group adjacent to twin tunneling.

\section{Case History}

2.1. Overview. The considered case history is a twin tunneling-by-shield tunneling machine for the construction of Hefei Metro Line 2 in Hefei, China. The twin tunneling passes underneath the Wulidun Overpass in the mileage range of SK26+050-SK26+450 between Qingyang Road Station and Xiyuan Road Station. The Wulidun Overpass, supported by a pile group, is located at the intersection of West Changjiang Road, Tunxi Road, and Hezuohua Road. It has connected the traffic in 17 flow directions. The maximum height of the Wulidun Overpass is $21 \mathrm{~m}$ from the ground surface. The superstructure of the Wulidun Overpass is a continuous beam on many supports. Figure 1 shows the location of the engineering site.

2.2. Parameters for the Ground, Tunnel, and Pile Group. The twin tunnels (i.e., the right and left tunnels) were excavated in a thick clay stratum and have a cover depth of $20 \mathrm{~m}$, as depicted in Figure 2. The clay's engineering properties have been investigated by the authors and reported elsewhere [49-52]. The horizontal distance between the tunnel axes of the left and right tunnels is $28 \mathrm{~m}$. The pile group foundation is composed of 8 bored concrete piles of $1 \mathrm{~m}$ in diameter and $30 \mathrm{~m}$ in length. The distance between the centers of any two adjacent piles in the pile group foundation is $3 \mathrm{~m}$. The shortest distance between the pile group foundation and the left tunnel is $3 \mathrm{~m}$. Three different strata (i.e., backfill soil, clay, and weathered rock) are penetrated by the pile group foundation. The pile cap is $12 \mathrm{~m}$ in length, $6 \mathrm{~m}$ in width, and $1 \mathrm{~m}$ in height. Besides, the tunnel segments' internal diameter, thickness, and ring width are 5.4, 0.3, and $1.5 \mathrm{~m}$, respectively. The thickness of the grouting in the TBM tail interspace is $0.1 \mathrm{~m}$.

2.3. Instrumentation. To ensure stability and safety for tunneling construction and the adjacent pile group, instruments of different types were installed at various positions to monitor the responses of the tunnel structure, ground surface, and pile group at different tunneling steps. The measurement items, instruments, and monitoring point arrangement for the considered case history are summarized in Table 1. As shown in the table, the measurement items include the ground surface settlement, tunnel vertical displacement, tunnel peripheral convergence, pile cap settlement, pile cap tilt, pile cap differential settlement, pile cap fissure, and Wulidun Overpass beam stress. The adopted instruments consist of the precise leveling instrument, steel ruler, convergence gauge, laser range finder, total station, reflector, crack gauge, vernier caliper, and taseometer. Figure 3 depicts the arrangement of the monitoring points in the field. The distance between two neighboring monitoring points can be $2.5,3.5$, or $5 \mathrm{~m}$. The symbol "DBC" represents the instrumented section in the transverse direction 


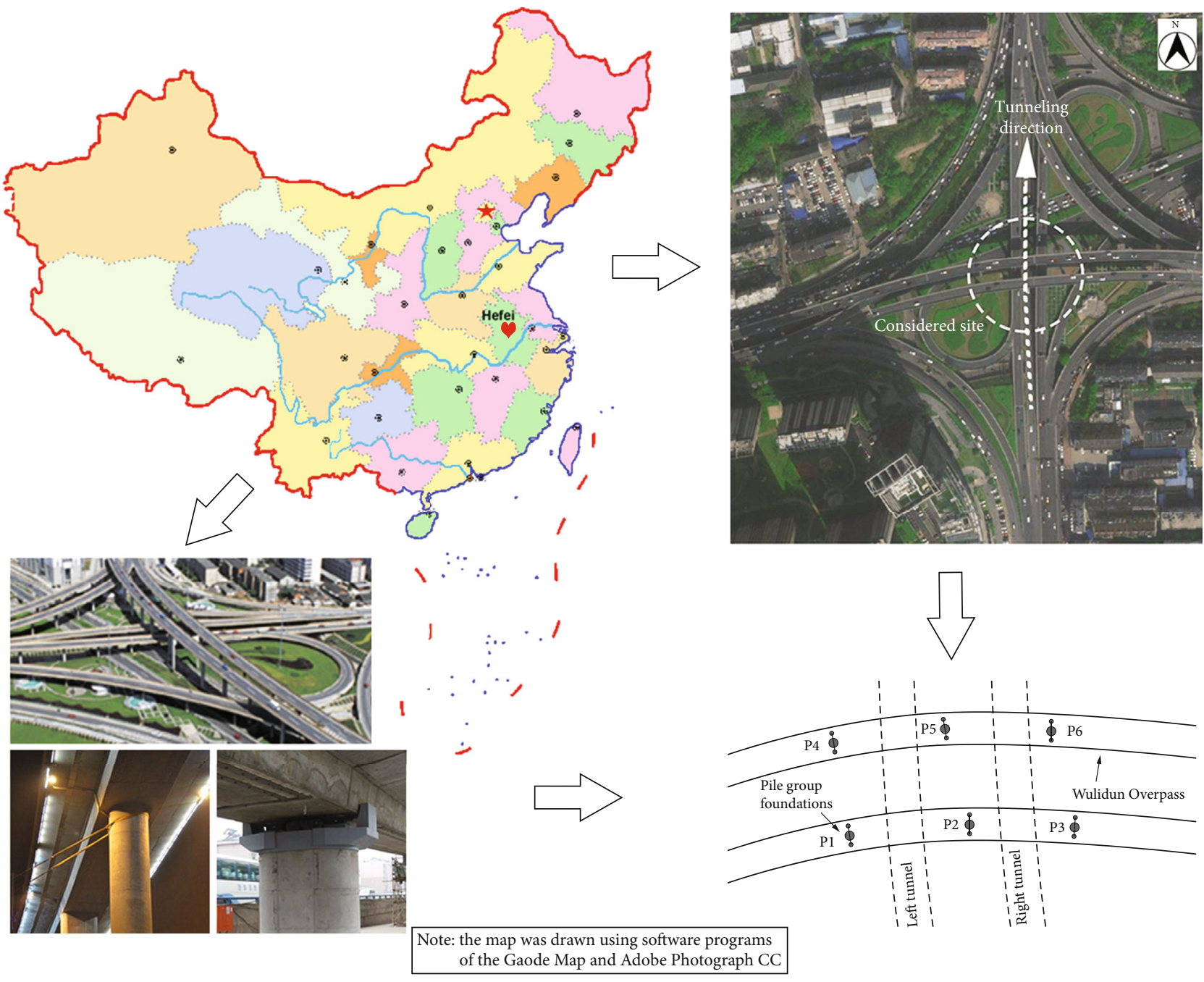

FIgURE 1: Engineering site.

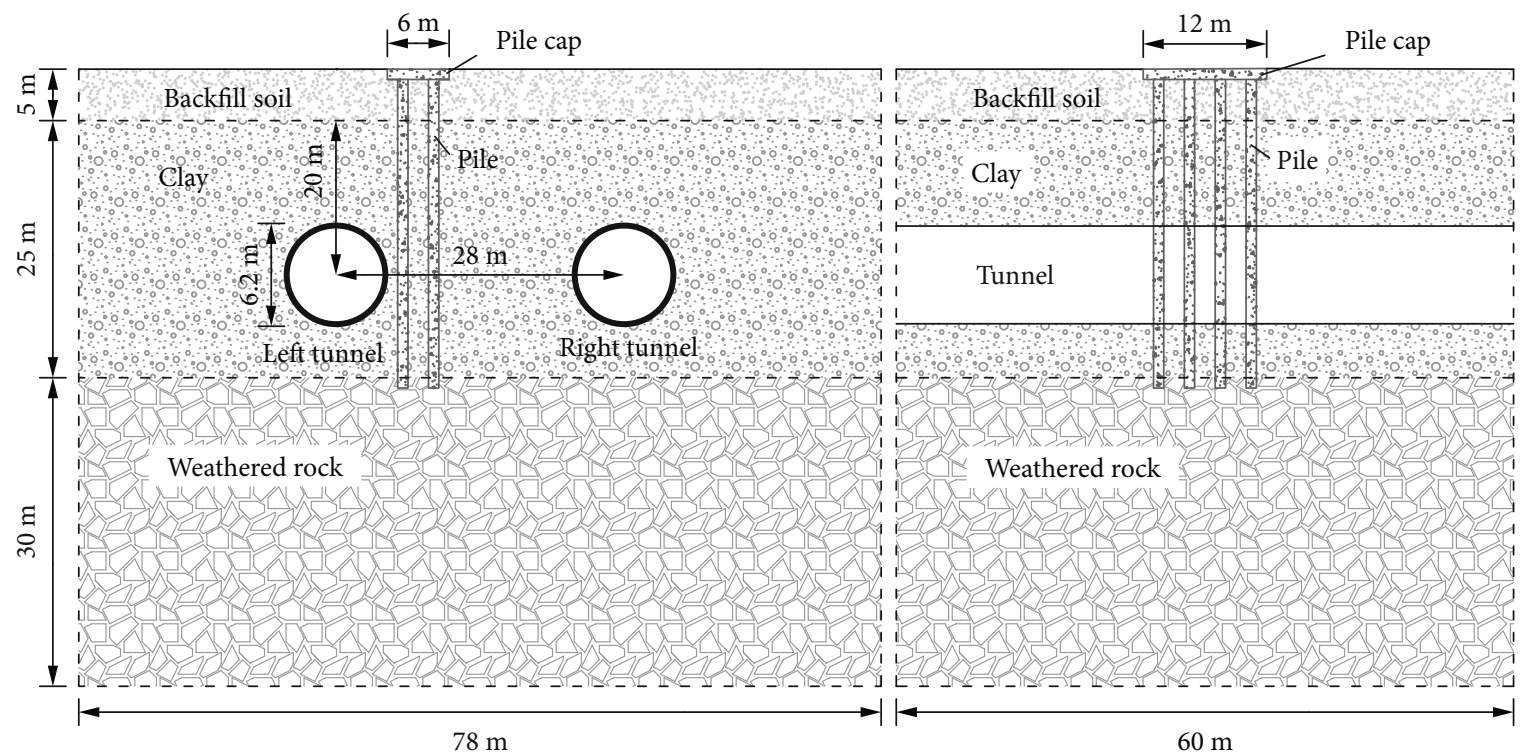

(a) Front view

(b) Side view

Figure 2: Front and side views of the considered engineering case. 
TABLE 1: Summary of the in situ monitoring information.

\begin{tabular}{lcc}
\hline Item & Instrument & Arrangement \\
\hline Ground surface settlement & Precise leveling instrument; steel ruler & Interval of instrumented sections = 20 m; built-up areas \\
Tunnel vertical displacement & Precise leveling instrument; steel ruler & Interval of instrumented sections =5 m \\
Tunnel peripheral convergence & Convergence gauge; laser range finder & Interval of instrumented sections $=5 \mathrm{~m}$ \\
Pile cap settlement & Precise leveling instrument; steel ruler & On the two sides of each pier perpendicular to the tunnel axis \\
Pile cap tilt & Total station; reflector & On the two sides of each pier perpendicular to the tunnel axis \\
Pile cap differential settlement & Precise leveling instrument; steel ruler & Each pier \\
Pile cap fissure & Crack gauge; vernier caliper & On the two sides of each fissure \\
Wulidun Overpass beam stress & Taseometer & In the middle of the bridge beam and slab structure \\
\hline
\end{tabular}

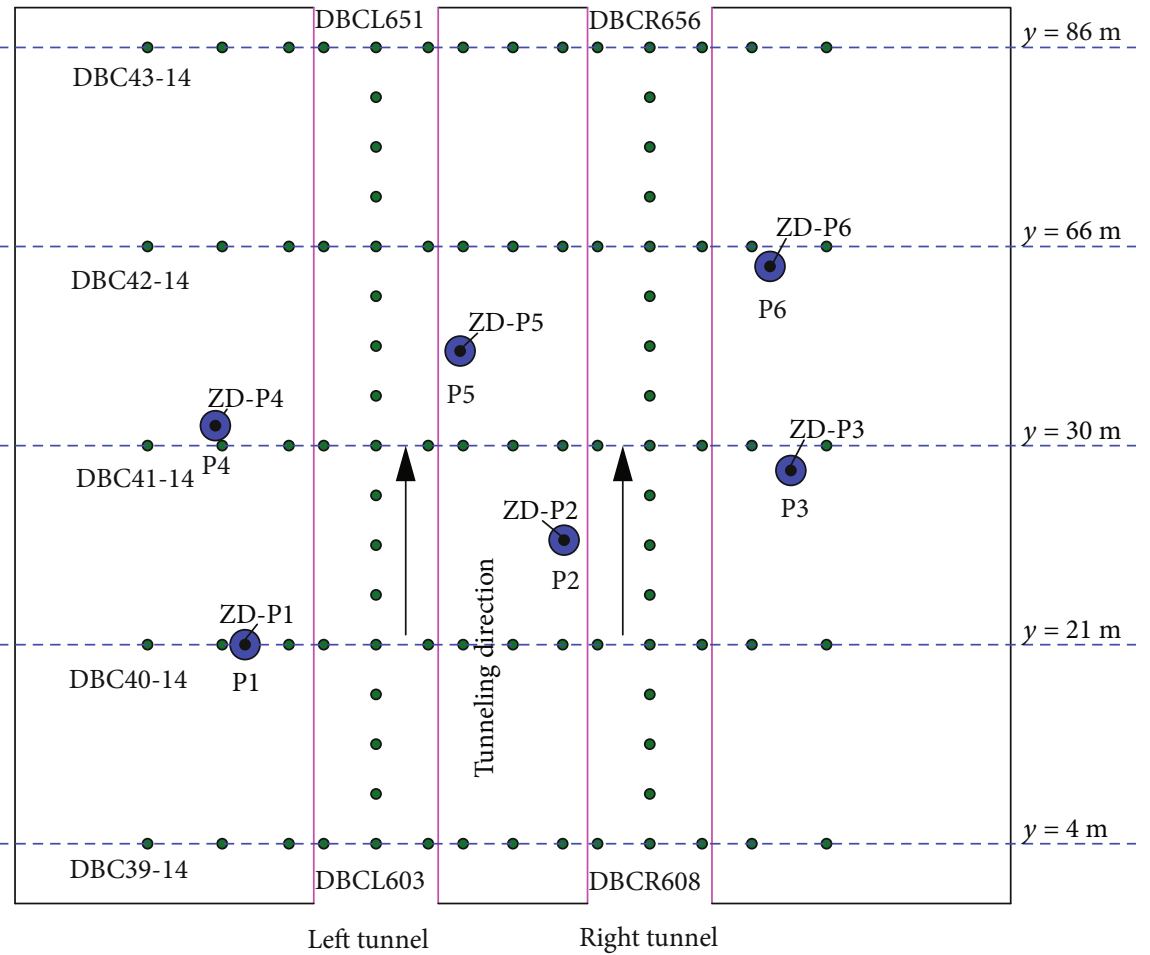

FiguRE 3: Schematic diagram of the in situ monitoring point arrangement.

along the tunnel axis. "DBCL" and "DBCR" denote, respectively, instrumented sections in the tunnel axis direction above the left and right tunnels.

\section{Three-Dimensional Finite Element Analysis}

3.1. Modeling of the Pile Group, Strata, and Their Interaction. Numerical modeling of the pile group, soil strata, and pilesoil interaction is established using the finite element method. Figure 4 shows the meshing of the numerical models based on MIDAS GTS NX [53]. A spatial model size of $78 \mathrm{~m} \times 60 \mathrm{~m} \times 60 \mathrm{~m}$ (i.e., $x \times y \times z$ ) is selected for the purpose of minimizing the potential boundary effects as much as possible. As for the model boundary conditions, normal restraints are applied to the four vertical boundaries and base boundary, while the top boundary is free. Therefore, there is no normal movement for the vertical boundaries and no movement for the base bound- ary. Tetrahedral elements are adopted here to mesh the soil, pile cap, lining segments, and bored concrete piles. The TBM shell and grouting are modeled using shell elements. Table 2 summarizes the mechanical parameters of the materials used in numerical modeling. In this table, the parameters for the geomaterials, including backfill soil, clay, and weathered rock, were obtained by performing in situ and laboratory tests. It is noted that the elasticity modulus of the weathered rock is significantly greater than that of the backfill soil and the clay, whereas the difference among the other four parameters of the three types of soils is not very significant. For the artificial materials (i.e., grouting, segment, shield, and pile), the parameters were obtained from design specifications or from empirical values. Note that there are no cohesion and no internal friction angle for these artificial materials as their constitutive behavior was simulated with a linear elastic model in the numerical analysis. 

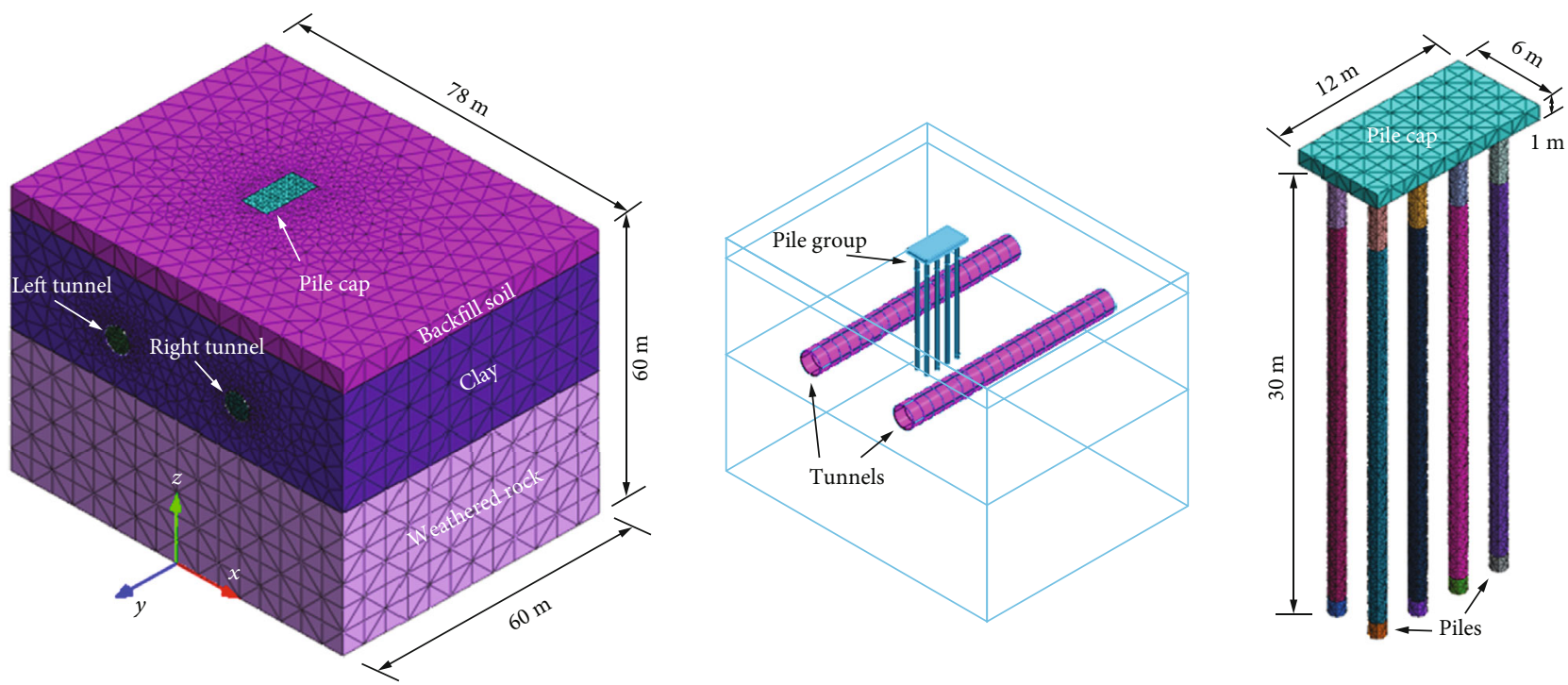

FIGURE 4: Meshing of numerical models.

TABLE 2: Material parameters for numerical analysis.

\begin{tabular}{lccccc}
\hline Material & Elasticity modulus $(\mathrm{MPa})$ & Unit weight $\left(\mathrm{kN} / \mathrm{m}^{3}\right)$ & Poisson's ratio & Cohesion $(\mathrm{kPa})$ & Internal friction angle $\left(^{\circ}\right)$ \\
\hline Backfill soil & 13 & 19 & 0.35 & 10 & 8 \\
Clay & 37 & 20.3 & 0.33 & 40 & 20 \\
Weathered rock & 100 & 26 & 0.3 & 35 & 30 \\
Grouting & 10 & 23.6 & 0.3 & $/$ & $/$ \\
Segment & 30000 & 24.5 & 0.2 & $/$ & $/$ \\
Shield & 200000 & 78.5 & 0.3 & $/$ & $/$ \\
Pile & 33000 & 25 & 0.2 & $/$ & $/$ \\
\hline
\end{tabular}

In numerical modeling, the interaction between the pile and the surrounding soil is simulated by generating interface elements in the pile-soil interface based on the Coulomb friction theory. A summary of the parameters for the interface elements generated in numerical modeling is presented in Table 3. As presented in Table 3, there are in total four different parameters required for the contact elements. Considerations on determining the magnitudes of the interfacial shear modulus, normal modulus, cohesion, and internal friction angle are presented as follows. The interface elements have a shear modulus of $80 \%$ of the elastic modulus of the piles. The normal modulus of the interface elements is taken as 10 times the shear modulus of the interface elements. For convenience, the cohesion and internal friction angle for the interface elements are regarded approximately to be equivalent to that of the surrounding soil in contact with the piles.

3.2. Modeling of Twin Tunneling. For numerically simulating the twin tunneling process, several assumptions have to be made. First, take no account of the effects of permeation and hydraulic pressure induced by groundwater. Second, assume that the soil strata are isotropic, homogeneous, elastic, perfectly plastic materials. Third, take no account of the ultimate consolidation settlement of soil.
Before tunneling, initial gravity stress is applied to soil strata. Then, reset the displacement of soil strata to zero. The weight of the overpass supported by the pile group is equivalent to a uniform load of $2 \mathrm{MPa}$ applying on the pile cap. Twin tunneling starts from $y=0 \mathrm{~m}$ and progresses step by step until reaching $y=60 \mathrm{~m}$. The length of two segments (i.e., $3 \mathrm{~m}$ ) is selected as the progressing distance of each step. During twin tunneling, the tunnel face of the left tunnel gets ahead of the tunnel face of the right tunnel with a distance of $30 \mathrm{~m}$ between these two tunnel faces, as shown in Figure 5.

The procedure for numerically simulating twin tunneling is as follows. First, remove the initial soil elements included in a progressing distance (i.e., $3 \mathrm{~m}$ ), apply a normal compressive stress of $0.2 \mathrm{MPa}$ on the tunnel face, and install two pieces of lining segments under the protection of the TBM shell. Second, progress the TBM for a progressing distance of $3 \mathrm{~m}$ and grout in the interspace of the TBM tail with a grouting pressure of $0.2 \mathrm{MPa}$. Third, release the grouting pressure after the hardening of the grout is achieved. Repeat the aforementioned three steps until finishing twin tunneling.

3.3. Parametric Analysis. The finite element method has been used in this research work for the analysis of pile group responses to twin tunneling at different distances between 
TABLE 3: Parameters for contact elements.

\begin{tabular}{lc}
\hline Parameter & Value \\
\hline Shear modulus $(\mathrm{MPa})$ & 26400 \\
Normal modulus $(\mathrm{MPa})$ & 264000 \\
Cohesion $(\mathrm{kPa})$ & 36 \\
Internal friction angle $\left({ }^{\circ}\right)$ & 28 \\
\hline
\end{tabular}

the tunnel and the pile, different distances between tunnel faces, and different pile lengths. Keeping the distance between the left and right tunnels constant, five different distances between the tunnel and the pile which are $3 \mathrm{~m}$ (i.e., $0.5 D(D$ is the tunnel diameter)), $6 \mathrm{~m}$ (i.e., $1 D), 9 \mathrm{~m}$ (i.e., 1.5 $D$ ), $12 \mathrm{~m}$ (i.e., $2 D$ ), and $15 \mathrm{~m}$ (i.e., $2.5 \mathrm{D}$ ) are considered. Note that the distance between the tunnel and the pile is the minimum horizontal distance between the left tunnel and the pile group. Also, five different distances between tunnel faces, defined as the difference in the $y$-coordinate values of the left tunnel face and the right tunnel face, are considered for capturing the effects of this parameter on the displacement and stress behavior of the pile group. The considered distances between tunnel faces are 10, 20, 30, 40, and $50 \mathrm{~m}$. The considered four different pile lengths are 10,20,30, and $40 \mathrm{~m}$.

\section{Development of Ground and Pile Responses with Advancing Tunneling Steps}

4.1. Ground Surface Settlements. The tunneling-induced ground surface settlements at $y=21 \mathrm{~m}$ by the 3D finite element analysis and in situ monitoring are shown in Figure 6. In general, a good agreement between the $3 \mathrm{D}$ finite element analysis and in situ monitoring results can be observed. This indicates that the 3D finite element method adopted in this study has the ability to well capture the responses of the ground surface to twin tunneling at different tunneling steps. Moreover, it can be seen that as the tunnel face approaches $y=21 \mathrm{~m}$, the ground surface settlements increase gradually. However, the rates of increases in the ground surface settlements decrease as the tunnel face exceeds $y=21 \mathrm{~m}$. The settlement versus step curves of steps 5 to 9 show that, when the distance between the left tunnel face and $y=21 \mathrm{~m}$ is less than $1 D$, the variation of the ground surface settlements reaches the maximum, which is $3.2 \mathrm{~mm}$. However, when that distance is larger than $2 D$, the variation of the ground surface settlements with progressing tunneling steps is relatively small with a maximum value of $1.3 \mathrm{~mm}$, as indicated by ground settlements of steps 13 to 32. Particularly, no matter what the tunneling step is, the ground surface settlement at the tunnel axis is larger than that at other locations. The maximum ground surface settlement, which is $6.9 \mathrm{~mm}$, is achieved at the left tunnel axis at tunneling step 32 .

The ground surface settlements at the right tunnel axis are similar in tendency to that at the left tunnel axis. However, the maximum variation of the ground surface settlements at the right tunnel axis when the right tunnel face is in the area of $\pm D$ with respect to $y=21 \mathrm{~m}$ is $3.6 \mathrm{~mm}$, which is slightly larger than that at the left tunnel (i.e., $3.2 \mathrm{~mm}$ ). The ultimate ground surface settlement at the right tunnel axis is the maximum, which is $8.4 \mathrm{~mm}$. In addition, previous studies have indicated that the tunneling influence zones depend primarily on parameters such as the tunnel diameter, tunnel cover depth, and soil parameters [54-56]. Based on the calculation methods used in the literature and the practical conditions presented in this research work, the diameter of the tunneling influence zones for twin tunneling is approximately $23 \mathrm{~m}$. Thus, obvious superimposed effects can be observed for the ground surface settlements between the two axes of the left tunnel and the right tunnel.

Due to the fact that the pile group is nearer to the left tunnel than to the right tunnel, the inhibiting effects of the pile cap on the ground surface settlement are more observable at the left tunnel axis compared to the right tunnel axis. Hence, the maximum superimposed effects of twin tunneling-induced ground settlements occur at a data collection point that is nearer to the left tunnel than to the right tunnel.

Figure 7 presents the ground surface settlements at $y=4$ $\mathrm{m}$ obtained by the 3D finite element analysis and in situ monitoring for various tunneling steps. A comparison between Figures 6 and 7 indicates that the settlement curves presented in Figure 6 are in a better symmetry with respect to $x=0$ compared to the settlement curves presented in Figure 7. It is indicated by Figure 7 that the ultimate ground surface settlements at the left tunnel axis and at the right tunnel axis are, respectively, $6.9 \mathrm{~mm}$ and $8.6 \mathrm{~mm}$. The maximum superimposed effects of twin tunneling-induced ground surface settlements occur almost in the lateral middle of the two tunnels, which is in good agreement with the ground surface settlements' tendency predicted using the Peck formula. Consequently, the pile-to-tunnel distance affects significantly the twin tunneling-induced ground surface settlements.

A comparison of the ground surface settlement at Point A and the pile cap settlement at Point B by the 3D finite element analysis and in situ monitoring is shown in Figure 8. Points A and B are at $y=30$, as depicted in Figure 5. The comparison indicates that when the distance between the left tunnel face and $y=30$ is less than $2.5 D$, the settlements at Points $\mathrm{A}$ and $\mathrm{B}$ increase with progressing tunneling steps at a relatively high rate. However, when that distance is larger than $2.5 D$, the rate of increase in the settlements at Points $\mathrm{A}$ and $\mathrm{B}$ reduces gradually until reaching a steady settlement. The ultimate settlements at Points A and B are, respectively, $3.6 \mathrm{~mm}$ and $4.6 \mathrm{~mm}$. During the whole tunneling process, the settlement at Point $\mathrm{A}$ is consistently larger than that at Point B. This is because the pile cap stiffness is greater than the ground stiffness. The stability of the pile group is reduced due to the relative displacement between the pile and the soil around the pile resulting from the differential settlements between them. Thus, special attention should be paid to that issue in practical engineering so as to avoid undesirable accidents.

4.2. Horizontal Pile Displacement. The finite element analysis results indicate comparable horizontal displacements for different piles in the group. Therefore, for convenience, in this section, only the horizontal displacement of Pile 1 is discussed. Figure 9 shows the variation of the horizontal 


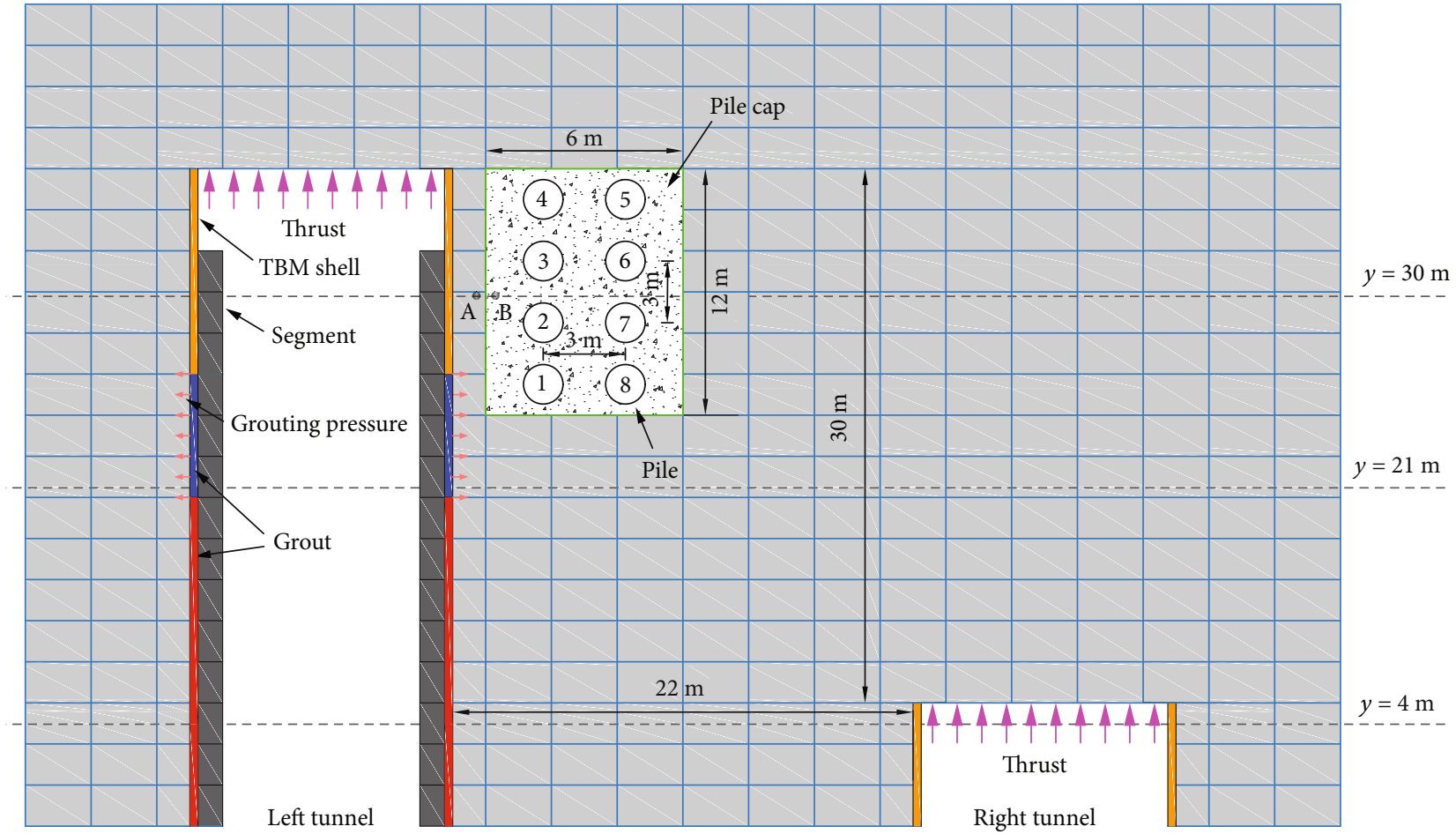

FIGURE 5: Schematic diagram of twin tunneling.

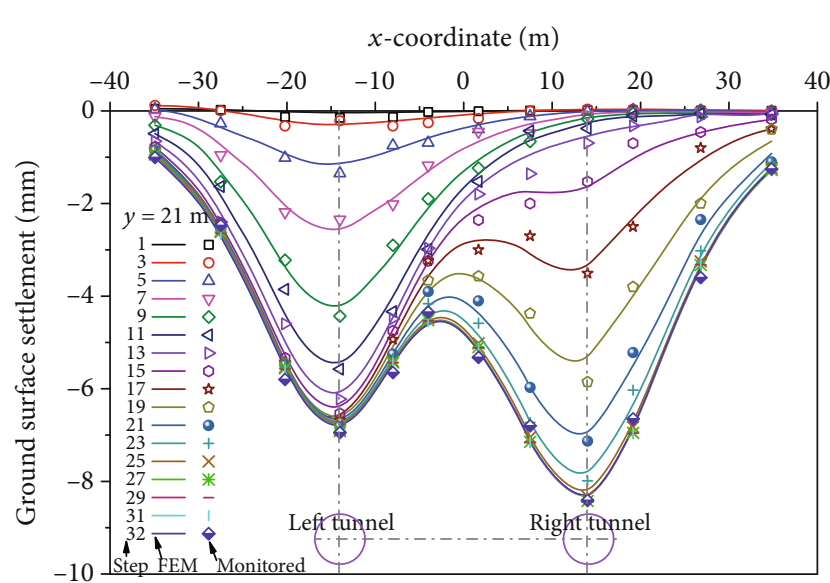

Figure 6: Ground surface settlement troughs at $y=21 \mathrm{~m}$ by the finite element method (FEM) and in situ monitoring.

displacement of Pile 1 with tunneling steps. Note that in Figure 9, the monitored horizontal pile displacement is only available at the pile top due to the difficulty in installing instruments on the pile shaft below the ground surface. It can be indicated that the horizontal displacement of Pile 1 is relatively small at tunneling steps 1 to 7 . During these tunneling steps, the shortest distance between the tunnel face and the pile group is larger than $2 D$. When this distance decreases from $2 D$ to $1.5 D$, the horizontal displacement of Pile 1 increases gradually. In addition, the distribution along the pile shaft of the horizontal displacement of Pile 1 is approximately S-shaped, with the horizontal displacements at the pile top and bottom being negative and at the cover depth of the tunnel centerline being positive.

During tunneling steps 7 to 10 , when the shortest distance between the tunnel face and the pile group is no more than $1 D$, the variation of the horizontal displacement of Pile 1 is the maximum. Similarly, the variation of the horizontal displacement of Pile 1 at the cover depth of the tunnel centerline reaches the maximum (i.e., $1.3 \mathrm{~mm}$ ). The maximum horizontal displacement of Pile 1 at the cover depth of the tunnel centerline (i.e., $1.9 \mathrm{~mm}$ ) is achieved at tunneling step 10. The negative displacements at the pile top and pile bottom remain increasing when the tunneling step progresses from 7 to 10 . Because the pile bottom is penetrated into bedrock, the horizontal displacement of the pile bottom is slightly smaller than that of the pile shaft above the pile bottom, which results in a point of inflection for the pile shaft. Progressing tunneling steps from 11 to 15 , it is found that the positive horizontal displacement at the cover depth of the tunnel centerline decreases, while the negative horizontal displacements at the pile top and pile bottom increase. The maximum negative horizontal displacement is $2.4 \mathrm{~mm}$. No apparent variation occurs of the horizontal displacement of Pile 1 after reaching tunneling step 15, when the shortest distance between the tunnel face and the pile group is larger than $3 D$. A point of inflection is generated at the pile shaft of the cover depth being slightly smaller than that of the tunnel centerline. The horizontal displacements of the pile shaft above the point of inflection decrease with an increase in the tunneling steps due to a relatively looser constraint that backfill soil poses on the pile shaft than clay.

In fact, during the whole tunneling process, the primary reason for a gradual increase in the positive horizontal 


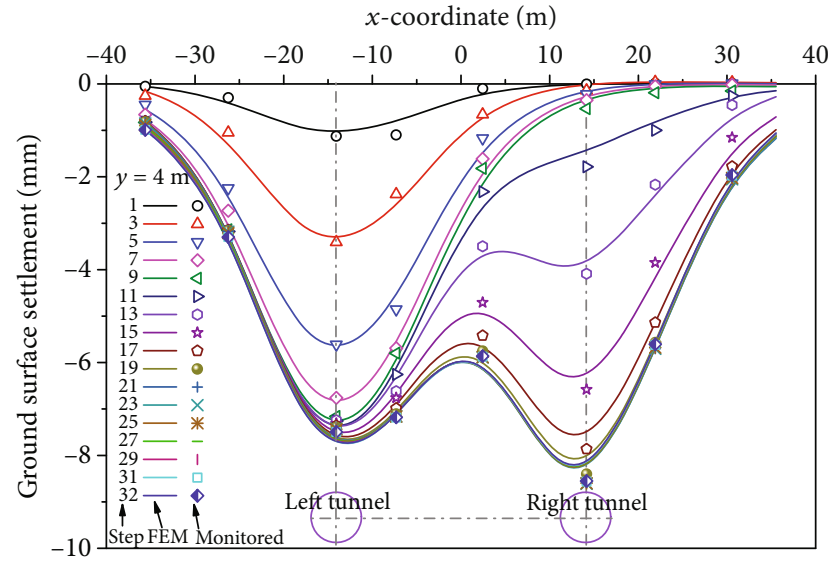

Figure 7: Ground surface settlement troughs at $y=4 \mathrm{~m}$ by the finite element method (FEM) and in situ monitoring.

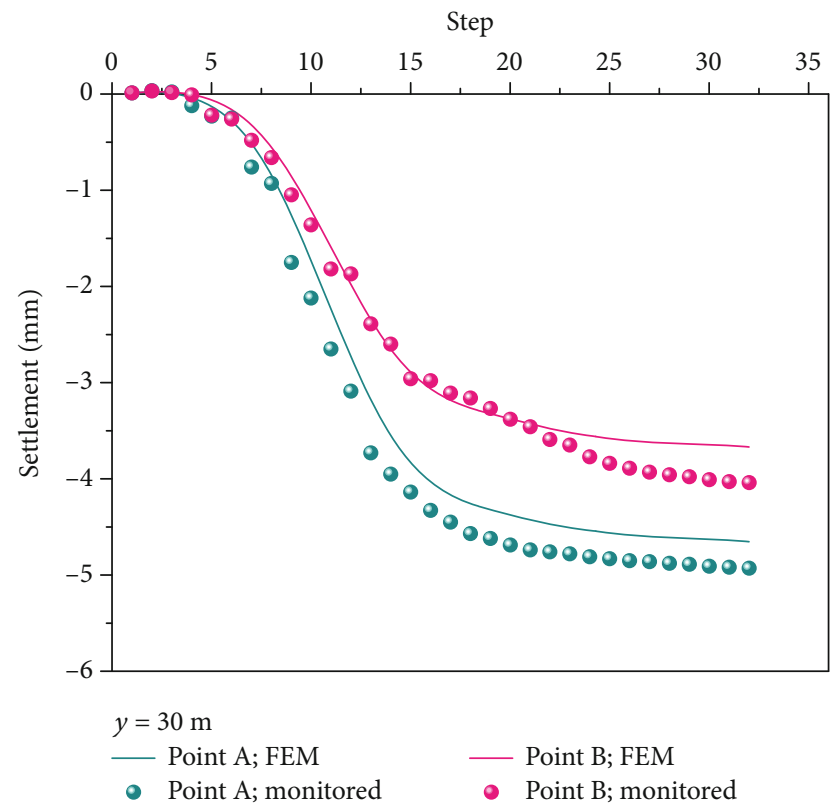

Figure 8: Settlements at Points A and B by the finite element method (FEM) and in situ monitoring.

displacement of Pile 1 is that the support pressure of the left tunnel is larger than the stress-releasing effects of the soil around the left tunnel induced by the left tunneling. However, the positive horizontal displacement of Pile 1 will be restrained and even reduced due to the gradual decrease in the left tunnel support pressure caused by the TBM shell's absence and hardening of the grout and due to the support pressure induced by the right tunneling.

Figure 10 shows horizontal displacements of different piles in the pile group foundation at tunneling step 32. For convenience, Piles 1,2,3, and 4, which are nearer to the left tunnel compared to the other four piles, are termed the front piles, and the other four piles (i.e., Piles 5, 6, 7, and 8) are termed the back piles. It can be seen from Figure 10 that the ultimate horizontal displacements of the front piles are

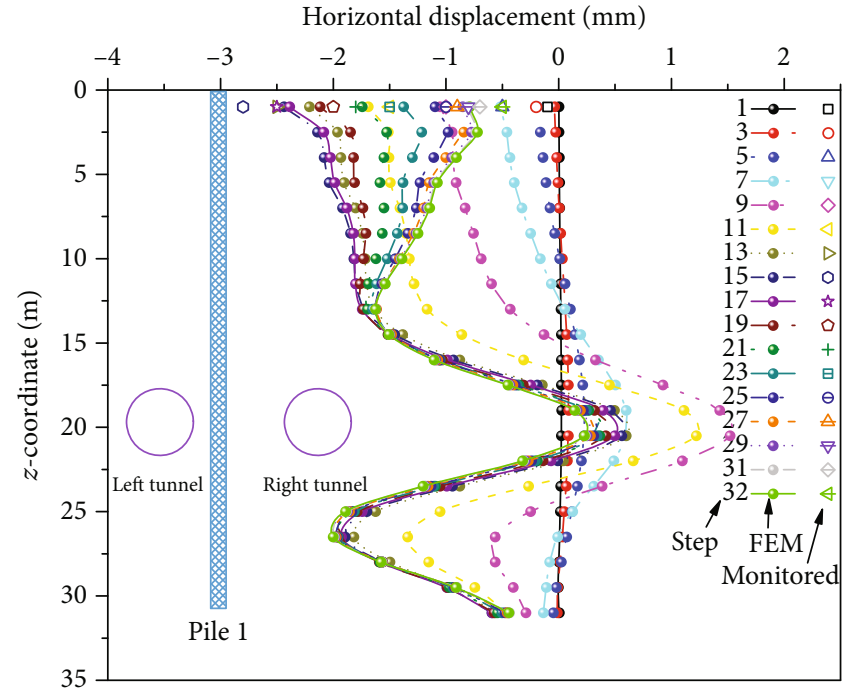

FIgURe 9: Horizontal displacements of Pile 1 at different tunneling steps.

generally larger than that of the back piles, although their distributions along the pile shaft of the ultimate horizontal displacements are similar in form. The positive horizontal displacements of the front piles at the cover depth of the tunnel centerline are larger than that of the back piles, resulting from a larger support pressure of the left tunnel subjected by the front piles than by the back piles due to a relatively smaller distance between the front pile and the left tunnel.

Figure 10 also indicates that the negative horizontal displacements at pile tops and pile bottoms of the front piles are larger than that of the back piles. This involves two reasons, which are, first, a relatively larger value for the left tunneling-induced stress-releasing effects subjected by the front piles than by the back piles and, second, a smaller value for both the right tunneling-induced stress-releasing effects and the support pressure of the right tunnel resulting from the shielding effects of the back piles. Consequently, the distributions along the pile shaft of the horizontal displacement are similar in form between the front and back piles, but the magnitude of the horizontal displacement of the front piles is slightly larger than that of the back piles.

4.3. Vertical Pile Displacement. Figure 11 shows the variation of the vertical displacement of Pile 1 with tunneling steps. It is indicated that the pile top settles most, and the settlements at the pile shaft decrease gradually with an increase in the cover depth till reaching maxima at a cover depth. After this, the pile shaft heaves slightly. The settlement of Pile 1 is no more than $1 \mathrm{~mm}$ from tunneling steps 1 to 5 when the shortest distance between the tunnel face and the pile group exceeds $2 D$. The rate of increase in the vertical displacement of Pile 1 increases with progressing tunneling steps from 5 to 11 , during which the shortest distance between the tunnel face and the pile group reduces from $2 D$ to $1 D$. After reaching tunneling step 11, the rate of increase in the vertical displacement of Pile 1 starts to reduce until tunneling step 15, after which the vertical displacement of Pile 1 turns to be an 


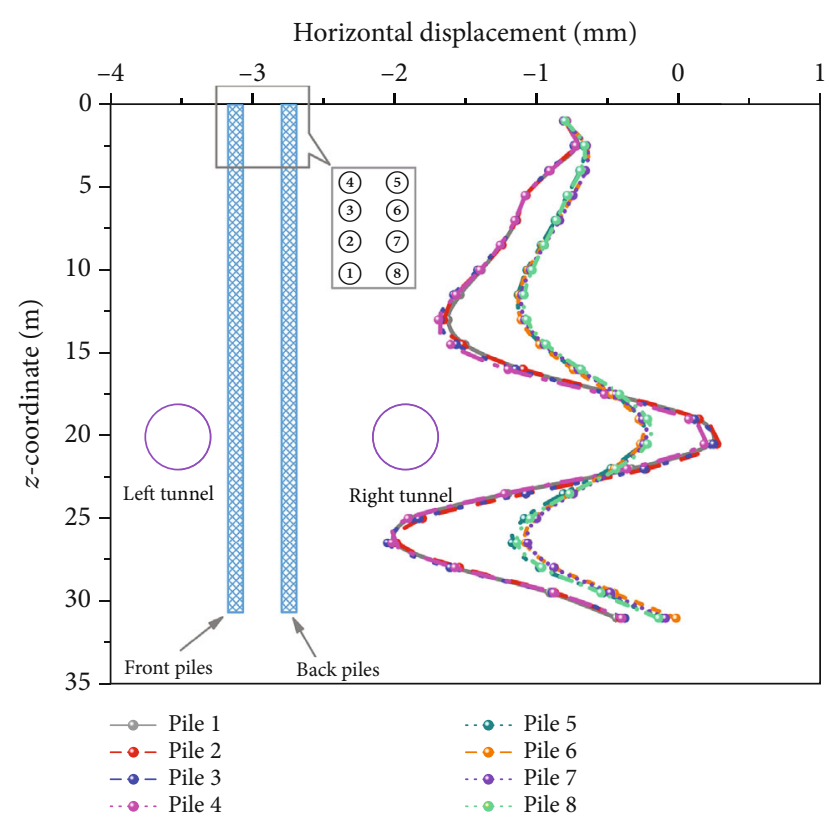

FIGURE 10: Horizontal pile displacements on completion of twin tunneling.

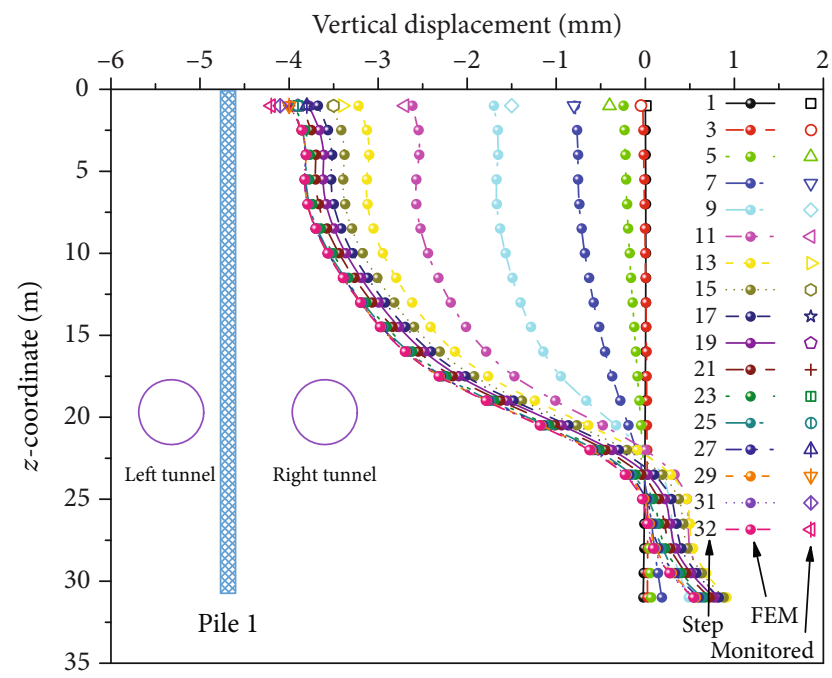

Figure 11: Vertical displacements of Pile 1 at different tunneling steps.

almost steady value. At last, the pile top settlement reaches the maximum with a value of $3.9 \mathrm{~mm}$, while a maximum heave (i.e., $0.5 \mathrm{~mm}$ ) appears at the pile bottom.

The vertical displacement of the pile and its distribution along the pile shaft are attributed to the tunneling-induced stress-releasing effects subjected by the soil around the tunnel, which can induce movements of the soil around the tunnel and of the pile penetrated in the soil to the tunnel centerline. Moreover, the magnitude and direction of this movement of the pile depend primarily on the relative location and distance between the tunnel centerline and the pile shaft.

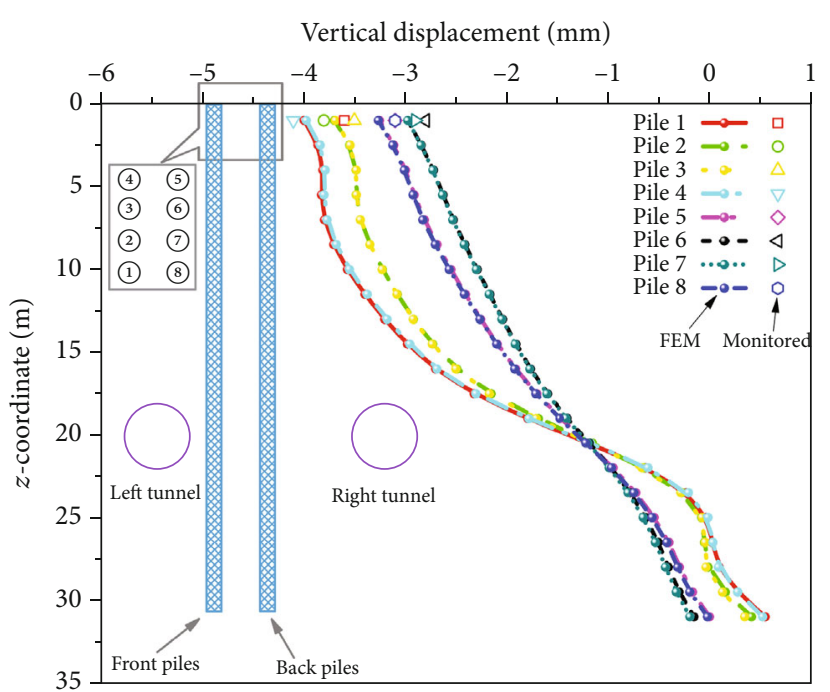

Figure 12: Vertical pile displacements on completion of twin tunneling.

It is observed from Figure 12 that the vertical displacements of the front piles are larger in magnitude than that of the back piles. Among the front piles, the two corner piles (i.e., Piles 1 and 4) settle most compared to the other front piles. But the vertical displacements of Piles 6 and 7 in the back piles are the minima. Nevertheless, the distributions along the pile shaft of the vertical displacement of all the piles in the pile group are almost identical. Thus, twin tunnelinginduced pile responses are varied for different piles in the pile group. By comparison, the corner piles in the pile group are more susceptible to twin tunneling than the middle piles, demonstrating that the interactions between piles in the pile group provide protection of the middle piles in the pile group against twin tunneling effects.

4.4. Axial Pile Stress. The distributions along the pile shaft of the axial stresses of different piles in the pile group are presented in Figure 13. It is observed that all the piles are under compression over the entire pile shaft with a most identical distribution form of axial pile stress. The compressive stress along the pile shaft increases from the ground surface to the cover depth of the tunnel centerline. After reaching the cover depth of the tunnel centerline, the magnitude of the compressive stress decreases with a further increase in the cover depth. Hence, the maximum compressive stress in Pile 1 (i.e., 17.3 MPa) is achieved at the cover depth of the tunnel centerline, while the compressive stress at the bottom of Pile 13 , which is $9.3 \mathrm{MPa}$, is the minimum.

Before twin tunneling, initial compressive stress exists in the pile group, which is generated by the pile weight and the uniform load applied on the pile cap. However, this initial compressive stress has been changed since the beginning of twin tunneling, resulting from the relative displacement between the pile shaft and the soil around the pile induced by the soil's stress-releasing effects. The magnitude of the relative displacement in the pile-soil interface depends primarily on the cover depth of the pile shaft. Above the pile shaft of the cover depth of the tunnel centerline, the relative 


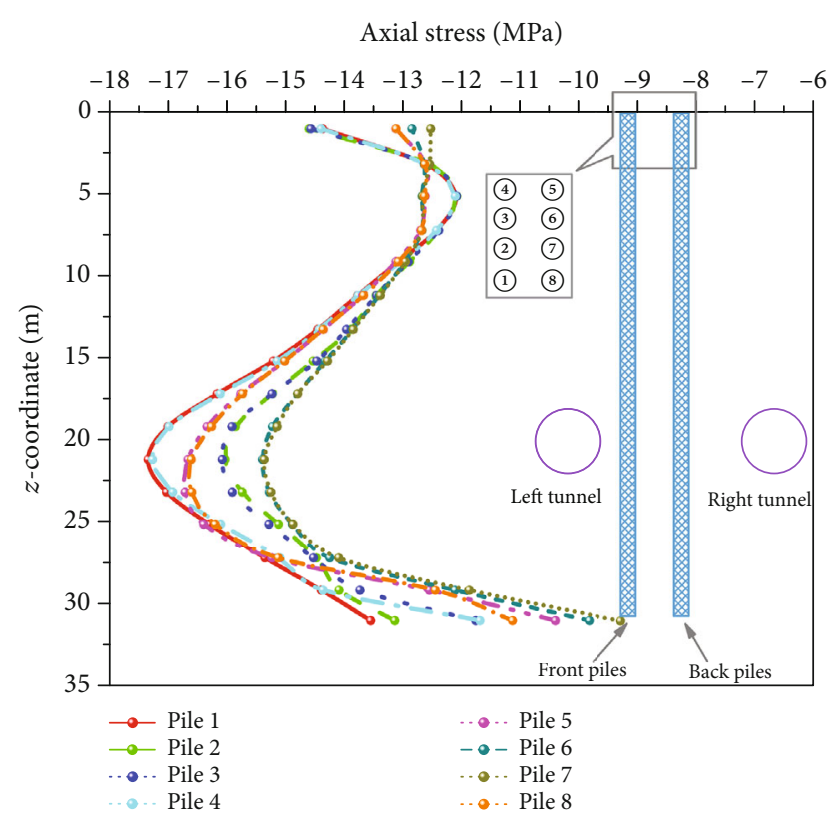

FIGURE 13: Axial pile stresses on completion of twin tunneling.

displacement in the pile-soil interface induces negative friction along the pile-soil interface, and the magnitude of which increases with an increase in the cover depth. On the contrary, positive friction has been induced along the pile-soil interface below the pile shaft of the cover depth of the tunnel centerline. Consequently, the magnitude of the twin tunneling-induced compressive stress increases with an increase in the cover depth of the pile shaft until reaching the cover depth of the tunnel centerline, after which a further increase in the cover depth of the pile shaft results in a reduction in the compressive stress along the pile shaft.

\section{Discussion}

5.1. Effect of the Distance between the Tunnel and the Pile. Figure 14 shows the variation of the twin tunnelinginduced horizontal displacement of Pile 1 with the distance between the tunnel and the pile. When the distance between the tunnel and the pile increases from $3 \mathrm{~m}$ to $9 \mathrm{~m}$, Pile 1 moves more further to the left tunnel, which means a reduction in the horizontal displacement of Pile 1. Particularly, the variation of the maximum horizontal displacement of Pile 1 is larger than that of any other horizontal displacement of the pile shaft. A rather small horizontal displacement ranging from -0.3 to $0.2 \mathrm{~mm}$ is produced of Pile 1 at a pile-to-tunnel distance of $9 \mathrm{~m}$. The pile group approaches the right tunnel gradually when the pile-to-tunnel distance increases from 9 to $15 \mathrm{~m}$. At this time, the horizontal displacement distribution along the pile shaft of Pile 1 becomes apposite to the case where the pile-to-tunnel distance is 3 or $6 \mathrm{~m}$.

Figure 15 presents the vertical displacements of Pile 1 induced by twin tunneling at different distances between the tunnel and the pile. Pile settlement occurs at all the considered distances between the tunnel and the pile. The effects of the left tunneling on pile settlement decrease with an

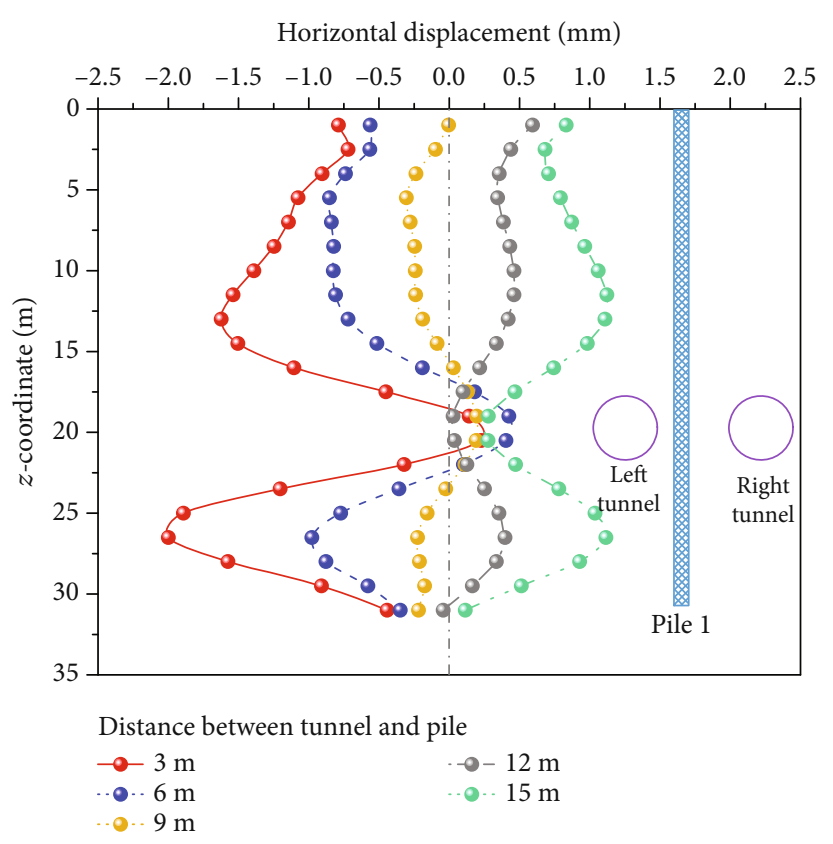

FIgURe 14: Horizontal displacements of Pile 1 on completion of twin tunneling at different pile-to-tunnel distances.

increase in the distance between the tunnel and the pile, which is characterized by a reduction in the vertical pile displacement. The pile top settlement reduces from 3.9 to $3 \mathrm{~mm}$, and the vertical displacement at the pile bottom changes from 0.5 to $-0.1 \mathrm{~mm}$ when increasing the distance between the tunnel and the pile from 3 to $12 \mathrm{~m}$. The pile group becomes closer to the right tunnel than to the left tunnel at a distance between the tunnel and the pile of $15 \mathrm{~m}$. In this circumstance, the vertical pile displacement is affected predominantly by the right tunnel rather than the left tunnel.

The axial stress of Pile 1 induced by twin tunneling at different distances between the tunnel and the pile is shown in Figure 16. It is shown that the axial stress distributions along the pile shaft are consistent at different distances between the tunnel and the pile. The maximum axial pile stress reduces slightly with an increase in the distance between the tunnel and the pile due to a lower magnitude of the relative displacement in the pile-soil interface.

Consequently, the horizontal pile displacement is most susceptible to the distance between the tunnel and the pile compared to the other responses of the pile group to twin tunneling. Thus, in engineering practices, a larger distance between the tunnel and the pile is recommended for twin tunneling adjacent to an existing pile group foundation. Moreover, it should be taken into consideration that the distance between the left and right tunnels is subjected to constraints. By comparison, the optimal distance between the tunnel and the pile for the engineering case presented herein is $9 \mathrm{~m}$. More importantly, a recommendation can be made for the design of twin tunneling adjacent to an existing pile group that the pile group should be placed in the middle of the left and right tunnels in order to minimize the adverse effects of twin tunneling on pile group responses. 


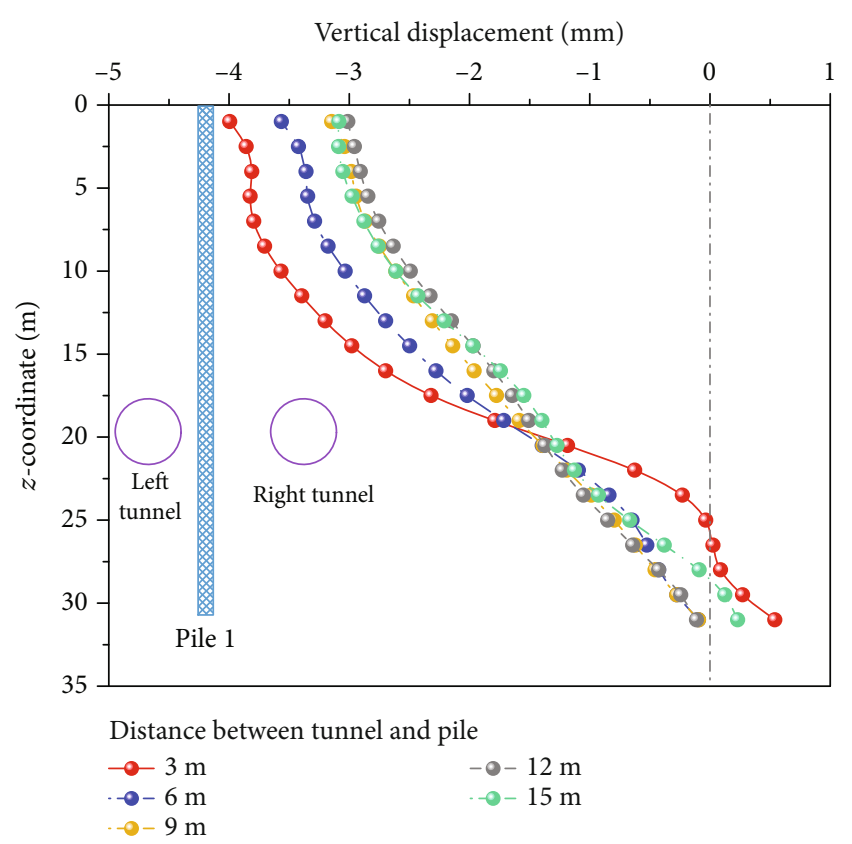

FIGURE 15: Vertical displacements of Pile 1 on completion of twin tunneling at different pile-to-tunnel distances.

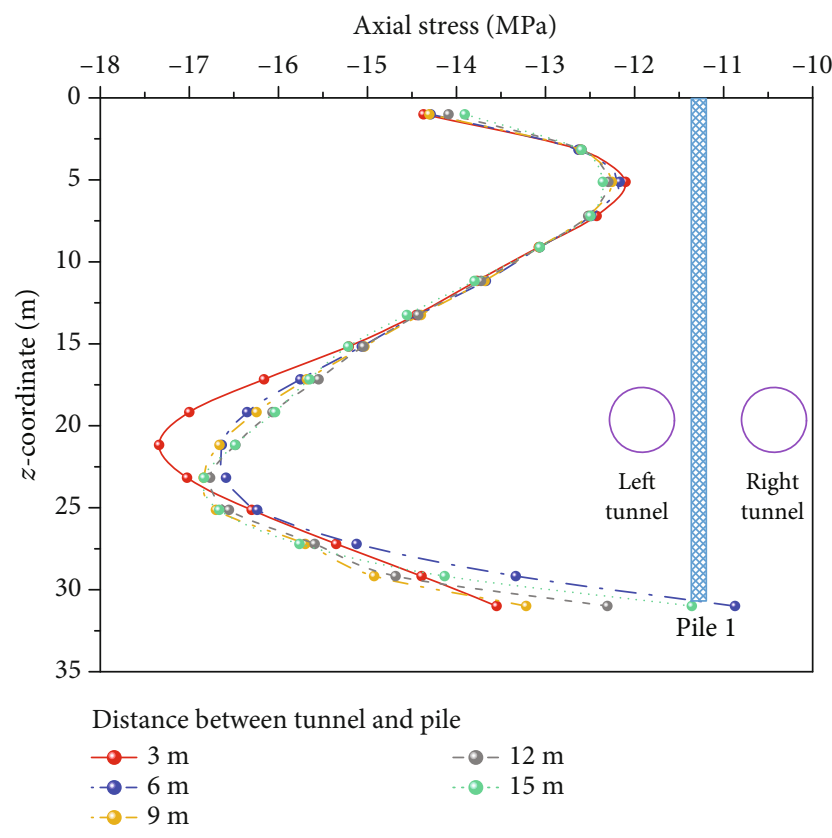

Figure 16: Axial displacements of Pile 1 on completion of twin tunneling at different pile-to-tunnel distances.

5.2. Effect of the Distance between Tunnel Faces. Figure 17 shows the variations of the maximum positive and negative horizontal displacements of Pile 1 on completion of twin tunneling with the distance between tunnel faces. From this figure, it can be indicated that both the maximum positive and negative horizontal displacements increase nonlinearly with an increase in the distance between tunnel faces. However, the rate of the increase becomes smaller at a larger mag-

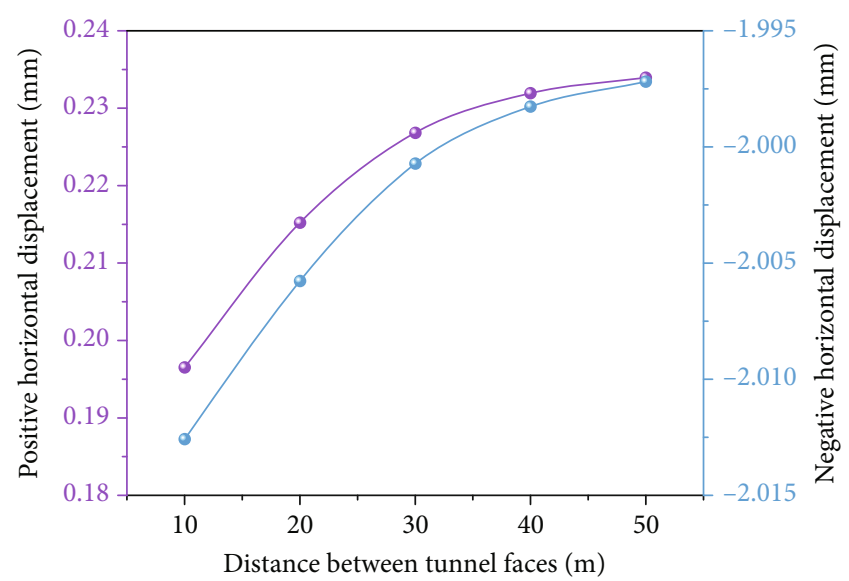

Pile 1

-๑- Positive

-๑- Negative

Figure 17: Maximum horizontal displacements of Pile 1 on completion of twin tunneling at different tunnel face-to-face distances.

nitude of the distance between tunnel faces. When the distance increases from 10 to $50 \mathrm{~m}$, the maximum positive and negative horizontal displacements increase, respectively, from approximately $0.195 \mathrm{~mm}$ to about $0.235 \mathrm{~mm}$ and from approximately $0.185 \mathrm{~mm}$ to about $-2.0175 \mathrm{~mm}$ to about $-1.9975 \mathrm{~mm}$. Nevertheless, the effect of the distance between tunnel faces on the maximum horizontal displacement of Pile 1 is negligible, as the variations in these values are generally less than $0.1 \mathrm{~mm}$ which can be also neglected.

Figure 18 presents the variations of the maximum positive and negative vertical displacements of Pile 1 on completion of twin tunneling with the distance between tunnel faces. It is shown that when the distance between tunnel faces increases from 10 to $50 \mathrm{~m}$, the variation of the maximum positive vertical displacement is less than $0.01 \mathrm{~mm}$, while the variation of the maximum negative vertical displacement is less than $0.25 \mathrm{~mm}$. These extremely small variations demonstrate that the distance between tunnel faces has a trivial effect on the maximum positive and negative vertical pile displacements induced by twin shield tunneling in clays. In addition, a further comparison between the variational trends in Figures 17 and 18 indicates that the maximum positive displacements in both the horizontal and vertical directions are one order of magnitude lower than the maximum negative displacements in both the horizontal and vertical directions. Hence, increasing the distance between tunnel faces within certain limits does benefit the stability of the pile group.

The variations of the maximum and minimum axial stresses of Pile 1 on completion of twin tunneling with the distance between tunnel faces are shown in Figure 19. It is observed that the maximum and minimum axial pile stresses increase slightly, while the difference between the maximum and minimum axial pile stresses decreases with an increase in the distance between tunnel faces. This demonstrates that a relatively uniform distribution of the axial pile stress along the pile shaft can be achieved by increasing the distance 


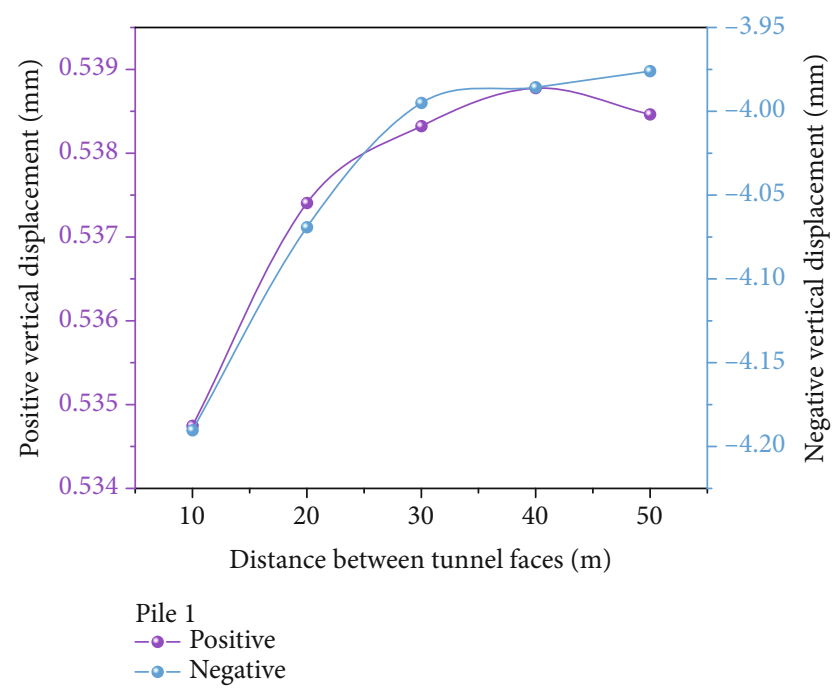

FIgUre 18: Maximum vertical displacements of Pile 1 on completion of twin tunneling at different tunnel face-to-face distances.

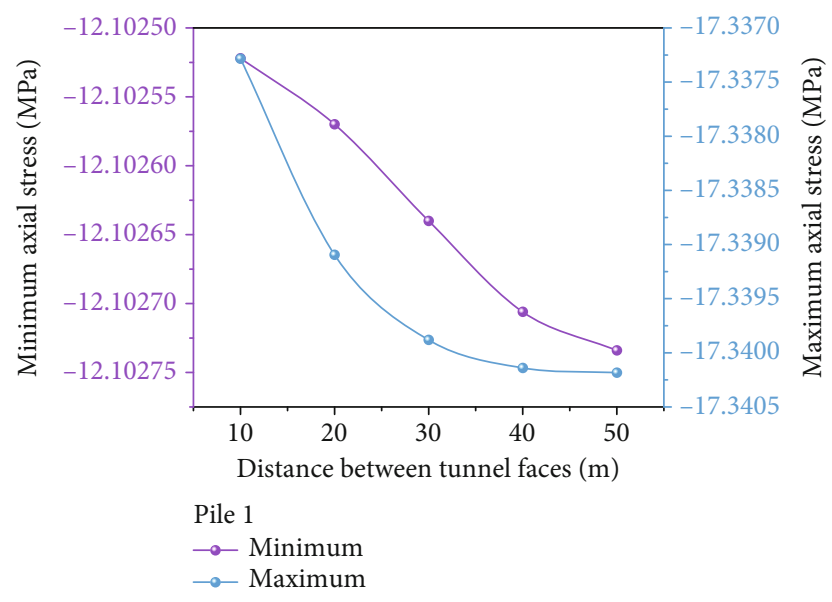

FIgURE 19: Maximum and minimum axial stresses of Pile 1 on completion of twin tunneling at different tunnel face-to-face distances.

between tunnel faces. After the distance between tunnel faces exceeds $30 \mathrm{~m}$, a further increase in the distance between tunnel faces results in no apparent variation in the horizontal and vertical displacements and axial pile stress. Moreover, a shorter construction period is favored in practical engineering practices for maximizing the economic benefits. Thus, $30 \mathrm{~m}$ has been chosen as the optimal distance between tunnel faces for the twin tunneling engineering case presented in this study for the purpose of achieving a balance between maximizing economic benefits and minimizing pile group responses induced by twin tunneling.

5.3. Effect of the Pile Length. Figure 20 presents the variation of the pile settlement with the cover depth for various pile lengths. It is found that the maximum pile settlement occurs at the pile bottom at relatively low pile lengths (i.e., 10 and 20 $\mathrm{m}$ ). At relatively high pile lengths (i.e., 30 and $40 \mathrm{~m}$ ), the

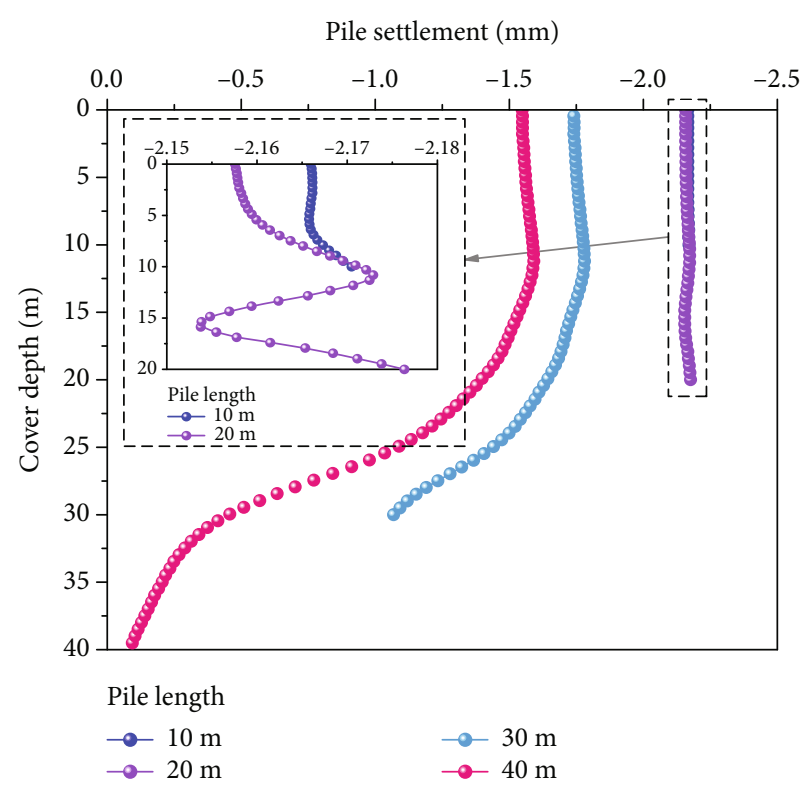

Figure 20: Variation of the pile settlement with the cover depth for different pile lengths.

maximum pile settlement occurs at a cover depth of appropriately $10 \mathrm{~m}$. In general, the maximum pile settlement decreases with an increase in the pile length. This is mainly because a higher pile length corresponds to a larger side friction between the pile and the soil and a greater bearing capacity of the soil at the pile bottom. Moreover, the difference between the settlements at the pile top and bottom increases with an increase in the pile length. At the pile length of $10 \mathrm{~m}$, the difference between the settlements at the pile top and bottom is $0.01 \mathrm{~mm}$. This value increases to $1.5 \mathrm{~mm}$ at the pile length of $40 \mathrm{~m}$. Nevertheless, an increase in the pile length from $10 \mathrm{~m}$ to $40 \mathrm{~m}$ leads to a decrease in the maximum pile settlement of $0.62 \mathrm{~mm}$ which is negligible. Therefore, it can be noted that the effect of the pile length is trivial on the magnitude of the pile settlement and is significant on the distribution of the pile settlement.

Figure 21 presents the variation of the horizontal pile displacement with the cover depth for different pile lengths. It can be seen that the distribution of the horizontal pile displacement along the pile shaft is similar at different pile lengths. At a pile length, the horizontal pile displacement decreases with an increase in the cover depth until reaching the cover depth of the twin tunnels (i.e., $20 \mathrm{~m}$ ). After this, the horizontal pile displacement increases with an increase in the cover depth until reaching a cover depth of appropriately $30 \mathrm{~m}$. With an increase in the pile length, the horizontal displacement at the pile top decreases till reaching the pile length of $30 \mathrm{~m}$ and then increases again when the pile length increases from 30 to $40 \mathrm{~m}$. Moreover, it seems that an increase in the pile length has a tendency to reduce the maximum negative horizontal pile displacement. However, the reduction in the maximum negative horizontal pile displacement due to an increase in the pile length is negligible.

Figure 22 presents the variations of the maximum and minimum axial pile stresses with the pile length. It is clear 


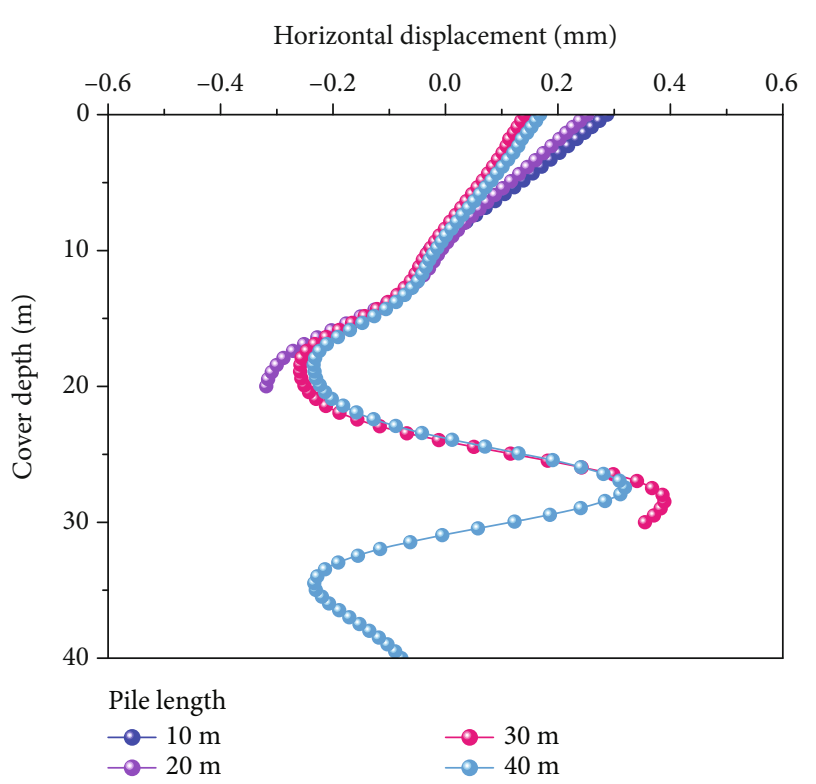

FIGURE 21: Variation of the horizontal pile displacement with the cover depth for different pile lengths.

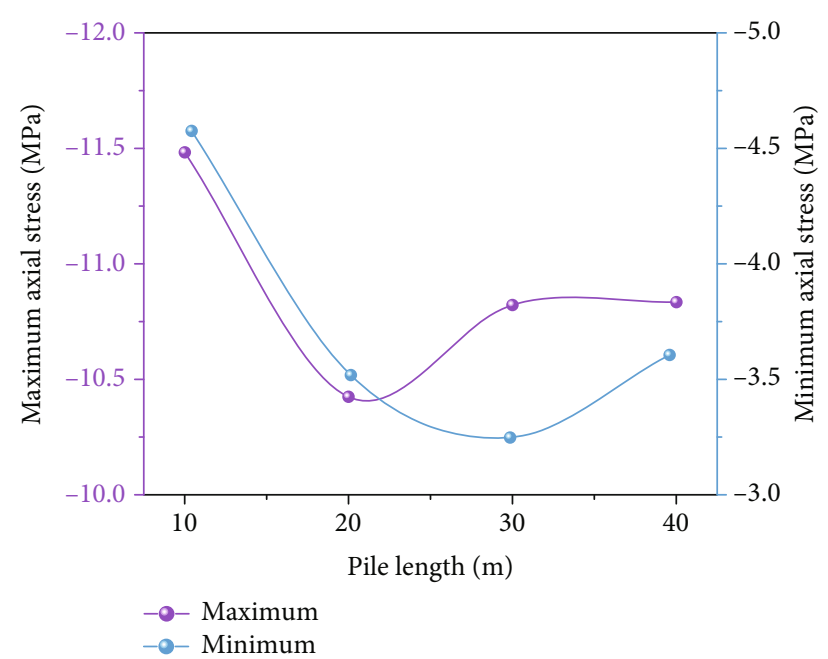

FIGURE 22: Variation of the maximum and minimum axial pile stresses with the pile length.

in Figure 22 that the relatively low maximum and minimum axial pile stresses can be achieved at a pile length ranging between 20 and $30 \mathrm{~m}$. At the pile length of $10 \mathrm{~m}$, the maximum and minimum axial pile stresses are far beyond that at the other three pile lengths. The reason for this is that the side friction between the pile and the soil is greater at a relatively low pile length.

\section{Conclusions}

Ground surface settlements and pile group responses induced by twin tunneling in clays have been investigated by performing $3 \mathrm{D}$ finite element analysis validated with the in situ monitoring data. The characteristics of the develop- ment of twin tunneling-induced ground surface settlements, horizontal and vertical pile displacements, and axial pile stresses with advancing tunneling steps were captured. The effects of the distance between the tunnel and the pile, the distance between tunnel faces, and the pile length on the pile group responses were discussed. The main conclusions that can be drawn from this study are summarized as follows:

(i) The ground surface settlements increase nonlinearly with progressing tunneling steps. The rates of increases in the ground surface settlements achieve maxima when the tunnel faces reach the positions under consideration. At any of the tunneling steps, the ground surface settlements are greater at the tunnel centerlines compared to the other positions. The maximum ground surface settlements at the centerlines of the left tunnel and right tunnel are, respectively, $7.9 \mathrm{~mm}$ and $8.6 \mathrm{~mm}$

(ii) The horizontal pile displacements change from being negative at the pile tops to being positive at the cover depth of the tunnel centerline. A maximum horizontal pile displacement of $1.5 \mathrm{~mm}$ is achieved at tunneling step 9. The vertical pile displacements decrease with an increase in the cover depth until reaching a cover depth of approximately $23 \mathrm{~mm}$, after which a pile heave occurs. The distributions along the pile shafts of axial pile stresses are similar for different piles in the pile group

(iii) Compared to the vertical pile displacements and axial pile stresses, the horizontal pile displacements are more susceptible to the distance between the tunnel and the pile. A distance between the tunnel and the pile of $9 \mathrm{~m}$ is found to be optimum for the considered engineering case. An increase in the distance between tunnel faces reduces the maximum negative horizontal and vertical pile displacements, improves the pile group stability, and facilitates a more uniform distribution along the pile shaft of the axial pile stress. The optimum distance between tunnel faces is found to be $30 \mathrm{~m}$. The effect of the pile length is more significant on the distribution of the pile settlement than on the magnitude of the pile settlement. The axial pile stresses reach the minimum when the pile length is slightly greater than the cover depth of the twin tunnels

\section{Data Availability}

Some or all data, models, or codes generated or used during the study are available from the corresponding authors by request.

\section{Conflicts of Interest}

The authors declare that they have no conflicts of interest. 


\section{Acknowledgments}

This research work was funded by the National Natural Science Foundation of China (51774107, 42077249) and the Opening Project of State Key Laboratory of Explosion Science and Technology, Beijing Institute of Technology (KFJJ21-03Z).

\section{References}

[1] Y. Xiang, S. He, Z. Cui, and S. Ma, "A subsurface "drift and pile" protection scheme for the construction of a shallow metro tunnel," Tunnelling and Underground Space Technology, vol. 20, no. 1, pp. 1-5, 2005.

[2] Q. Fang, D. Zhang, and L. N. Y. Wong, "Shallow tunnelling method (STM) for subway station construction in soft ground," Tunnelling and Underground Space Technology, vol. 29, pp. 10-30, 2012.

[3] K. H. Park, "Elastic solution for tunneling-induced ground movements in clays," International Journal of Geomechanics, vol. 4, no. 4, pp. 310-318, 2004.

[4] M. Nematollahi and D. Dias, "Three-dimensional numerical simulation of pile-twin tunnels interaction - case of the Shiraz subway line," Tunnelling and Underground Space Technology, vol. 86, pp. 75-88, 2019.

[5] F. Basile, "Effects of tunnelling on pile foundations," Soils and Foundations, vol. 54, no. 3, pp. 280-295, 2014.

[6] C. Liu, Z. Zhang, and R. A. Regueiro, "Pile and pile group response to tunnelling using a large diameter slurry shield case study in Shanghai," Computers and Geotechnics, vol. 59, pp. 21-43, 2014.

[7] Y. Wang, C. H. Li, and J. Q. Han, "On the effect of stress amplitude on fracture and energy evolution of pre-flawed granite under uniaxial increasing-amplitude fatigue loads," Engineering Fracture Mechanics, vol. 240, article 107366, 2020.

[8] A. Davarpanah, R. Shirmohammadi, B. Mirshekari, and A. Aslani, "Analysis of hydraulic fracturing techniques: hybrid fuzzy approaches," Arabian Journal of Geosciences, vol. 12, no. 13, p. 402, 2019.

[9] L. Cao, D. Zhang, X. Shen, J. Su, H. Fang, and D. Su, "Horizontal mechanical responses of single pile due to urban tunnelling in multi-layered soils," Computers and Geotechnics, vol. 135, article 104164, 2021.

[10] F. Peng and S. Ma, "Analysis of experimental data on the effect of double-line parallel shield tunneling on the deformation of adjacent buildings," Alexandria Engineering Journal, vol. 60, no. 4, pp. 3957-3963, 2021.

[11] Y. Wang, Y. F. Yi, C. H. Li, and J. Q. Han, "Anisotropic fracture and energy characteristics of a Tibet marble exposed to multi-level constant-amplitude (MLCA) cyclic loads: a labscale testing," Engineering Fracture Mechanics, vol. 244, p. 107550, 2021.

[12] G. Mollon, D. Dias, and A.-H. Soubra, "Probabilistic analyses of tunneling-induced ground movements," Acta Geotechnica, vol. 8, no. 2, pp. 181-199, 2013.

[13] Z. Zhang, M. Huang, Y. Pan et al., "Analytical prediction of time-dependent behavior for tunneling-induced ground movements and stresses subjected to surcharge loading based on rheological mechanics," Computers and Geotechnics, vol. 129, p. 103858, 2021.
[14] J.-F. Zhu, R.-Q. Xu, and G.-B. Liu, "Analytical prediction for tunnelling-induced ground movements in sands considering disturbance," Tunnelling and Underground Space Technology, vol. 41, pp. 165-175, 2014.

[15] M. Zhu, L. Yu, X. Zhang, and A. Davarpanah, “Application of implicit pressure-explicit saturation method to predict filtrated mud saturation impact on the hydrocarbon reservoirs formation damage," Mathematics, vol. 8, no. 7, article 1057, 2020.

[16] S. Sun, M. Zhou, W. Lu, and A. Davarpanah, "Application of symmetry law in numerical modeling of hydraulic fracturing by finite element method," Symmetry, vol. 12, no. 7, article $1122,2020$.

[17] K. M. Neaupane and N. R. Adhikari, "Prediction of tunnelinginduced ground movement with the multi-layer perceptron," Tunnelling and Underground Space Technology, vol. 21, no. 2, pp. 151-159, 2006.

[18] Y.-S. Fang, C.-T. Wu, S.-F. Chen, and C. Liu, "An estimation of subsurface settlement due to shield tunneling," Tunnelling and Underground Space Technology, vol. 44, pp. 121-129, 2014.

[19] R. B. Peck, "Deep excavation and tunneling in soft ground," in Proceedings of the 7th International Conference on Soil Mechanics and Foundation Engineering, pp. 225-290, Mexico City, 1969.

[20] R. J. Mair, M. J. Gunn, and M. P. O’Reilly, "Ground movements around shallow tunnels in soft clay," in Proceedings of the 10th international conference on soil mechanics and foundation engineering, pp. 323-328, Stockholm, Sweden, 1981.

[21] B. M. New and M. P. O’Reilly, “Tunnelling induced ground movements, predicting their magnitude and effects," in Proceedings of the 4th Conference on Ground Movements and Structures, pp. 671-697, Cardiff, 1991.

[22] L. Z. Wang, L. L. Li, and X. J. Lv, "Complex variable solutions for tunneling-induced ground movement," International Journal of Geomechanics, vol. 9, no. 2, pp. 63-72, 2009.

[23] M. N. Vu, W. Broere, and J. Bosch, "Effects of cover depth on ground movements induced by shallow tunnelling," Tunnelling and Underground Space Technology, vol. 50, pp. 499506, 2015.

[24] N. Loganathan and H. G. Poulos, "Analytical prediction for tunneling-induced ground movements in clays," Journal of Geotechnical and Geoenvironmental Engineering, vol. 124, no. 9, pp. 846-856, 1998.

[25] T. B. Celestino, R. A. M. P. Gomes, and A. A. Bortolucci, "Errors in ground distortions due to settlement trough adjustment," Tunnelling and Underground Space Technology, vol. 15, no. 1, pp. 97-100, 2000.

[26] Y. Shi, J. Fu, J. Yang, C. Xu, and D. Geng, "Performance evaluation of long pipe roof for tunneling below existing highway based on field tests and numerical analysis: case study," International Journal of Geomechanics, vol. 17, no. 9, article 04017054, 2017.

[27] P. Guo, X. Gong, and Y. Wang, "Displacement and force analyses of braced structure of deep excavation considering unsymmetrical surcharge effect," Computers and Geotechnics, vol. 113, article 103102, 2019.

[28] P. Jongpradist, T. Kaewsri, A. Sawatparnich et al., "Development of tunneling influence zones for adjacent pile foundations by numerical analyses," Tunnelling and Underground Space Technology, vol. 34, pp. 96-109, 2013.

[29] S. W. Jacobsz, K. H. Bowers, N. A. Moss, and G. Zanardo, "The effects of tunnelling on piled structures on the CTRL," in 
Geotechnical Aspects of Underground Construction in Soft Ground, pp. 115-122, Taylor \& Francis Group, Amsterdam, 2005.

[30] J. Zhou, X. Shi, K. Du, X. Qiu, X. Li, and H. S. Mitri, "Feasibility of random-forest approach for prediction of ground settlements induced by the construction of a shield-driven tunnel," International Journal of Geomechanics, vol. 17, no. 6, article 04016129, 2017.

[31] M. A. Soomro, Y. Hong, C. W. W. Ng, H. Lu, and S. Peng, "Load transfer mechanism in pile group due to single tunnel advancement in stiff clay," Tunnelling and Underground Space Technology, vol. 45, pp. 63-72, 2015.

[32] Y. Xu and P. Guo, "Disturbance evolution behavior of loess soil under triaxial compression," Advances in Civil Engineering, vol. 2020, Article ID 4160898, 14 pages, 2020.

[33] R. Zhang, J. Zheng, and S. Yu, "Responses of piles subjected to excavation-induced vertical soil movement considering unloading effect and interfacial slip characteristics," Tunnelling and Underground Space Technology, vol. 36, pp. 66-79, 2013.

[34] Y. X. Wang, S. B. Shan, C. Zhang, and P. P. Guo, "Seismic response of tunnel lining structure in a thick expansive soil stratum," Tunnelling and Underground Space Technology, vol. 88, pp. 250-259, 2019.

[35] P. Guo, F. Liu, G. Lei et al., "Predicting response of constructed tunnel to adjacent excavation with dewatering," Geofluids, vol. 2021, Article ID 5548817, 17 pages, 2021.

[36] Y. Wang and M. Li, "Research on the deformation law of jointed surrounding rock during tunnel excavation based on hydromechanical coupling," Geofluids, vol. 2021, Article ID 5583940, 13 pages, 2021.

[37] E. Ieronymaki, A. J. Whittle, and H. H. Einstein, "Comparative study of the effects of three tunneling methods on ground movements in stiff clay," Tunnelling and Underground Space Technology, vol. 74, pp. 167-177, 2018.

[38] E. Cattoni, C. Miriano, L. Boco, and C. Tamagnini, “Timedependent ground movements induced by shield tunneling in soft clay: a parametric study," Acta Geotechnica, vol. 11, no. 6, pp. 1385-1399, 2016.

[39] J. S. Shiau, M. S. Sams, J. Zhang, and R. J. Kemp, "Settlement analyses of underground circular tunneling in soft clay," in 8th International Symposium on Geotechnical Aspects of Underground Construction in Soft Ground, Seoul, South Korea, 2014.

[40] M. Son, "Response analysis of nearby structures to tunnelinginduced ground movements in clay soils," Tunnelling and Underground Space Technology, vol. 56, pp. 90-104, 2016.

[41] R. G. Laver, Z. Li, and K. Soga, "Method to evaluate the longterm surface movements by tunneling in London clay," Journal of Geotechnical and Geoenvironmental Engineering, vol. 143, article 06016023, 2016.

[42] H. Sun, J. Zhang, G. Zhao, and H. Wang, "Tunnel behaviour caused by basement excavation in clay," Geofluids, vol. 2021, Article ID 5570846, 11 pages, 2021.

[43] T. I. Addenbrooke and D. M. Potts, "Twin tunnel interaction: surface and subsurface effects," International Journal of Geomechanics, vol. 1, no. 2, pp. 249-271, 2001.

[44] A. Mirhabibi and A. Soroush, "Effects of building threedimensional modeling type on twin tunneling-induced ground settlement," Tunnelling and Underground Space Technology, vol. 38, pp. 224-234, 2013.
[45] P. Guo, X. Gong, Y. Wang, H. Lin, and Y. Zhao, "Minimum cover depth estimation for underwater shield tunnels," Tunnelling and Underground Space Technology, vol. 115, p. 104027, 2021.

[46] Y. Hong, M. A. Soomro, and C. W. W. Ng, "Settlement and load transfer mechanism of pile group due to side-by-side twin tunnelling," Computers and Geotechnics, vol. 64, pp. 105-119, 2015.

[47] C. W. W. Ng, H. Lu, and S. Y. Peng, "Three-dimensional centrifuge modelling of the effects of twin tunnelling on an existing pile," Tunnelling and Underground Space Technology, vol. 35, pp. 189-199, 2013.

[48] M. A. Soomro, C. W. W. Ng, N. A. Memon, and R. Bhanbhro, "Lateral behaviour of a pile group due to side-by-side twin tunnelling in dry sand: 3D centrifuge tests and numerical modelling," Computers and Geotechnics, vol. 101, pp. 48-64, 2018.

[49] Y. Wang, P. Guo, F. Dai, X. Li, Y. Zhao, and Y. Liu, "Behavior and modeling of fiber-reinforced clay under triaxial compression by combining the superposition method with the energybased homogenization technique," International Journal of Geomechanics, vol. 18, no. 12, article 04018172, 2018.

[50] Y. Wang, P. Guo, X. Li, H. Lin, Y. Liu, and H. Yuan, "Behavior of fiber-reinforced and lime-stabilized clayey soil in triaxial tests," Applied Sciences, vol. 9, no. 5, p. 900, 2019.

[51] Y. X. Wang, P. P. Guo, W. X. Ren et al., "Laboratory investigation on strength characteristics of expansive soil treated with jute fiber reinforcement," International Journal of Geomechanics, vol. 17, no. 11, article 04017101, 2017.

[52] Y. Wang, P. Guo, S. Shan, H. Yuan, and B. Yuan, "Study on strength influence mechanism of fiber-reinforced expansive soil using jute," Geotechnical and Geological Engineering, vol. 34, pp. 1079-1088, 2016.

[53] M. P. Komu, U. Guney, T. E. Kilickaya, and C. Gokceoglu, "Using 3D numerical analysis for the assessment of tunnellandslide relationship: Bahce-Nurdag tunnel (south of Turkey)," Geotechnical and Geological Engineering, vol. 38, no. 2, pp. 1237-1254, 2020.

[54] S. L. Chen, M. W. Gui, and M. C. Yang, "Applicability of the principle of superposition in estimating ground surface settlement of twin- and quadruple-tube tunnels," Tunnelling and Underground Space Technology, vol. 28, pp. 135-149, 2012.

[55] D. Jin, Z. Zhang, and D. Yuan, "Effect of dynamic cutterhead on face stability in EPB shield tunneling," Tunnelling and Underground Space Technology, vol. 110, p. 103827, 2021.

[56] D. Selemetas, "The response of full-scale piles and pile structures to tunneling, [Ph.D. thesis]," Cambridge University, 2005. 